\title{
LESÃO PERIFÉRICA DE CÉLULAS GIGANTES - RELATO DE CASO CLÍNICO
}

Mariana Motta LEVIEN, Thiago Rodrigo PASQUALOTTO, Fabiano GALINA, Cleto Mariosvaldo PIAZZETTA

A lesão periférica de células gigantes (LPCG) é definida como uma lesão benigna, proliferativa e reacional do tecido conjuntivo fibroso ou do periósteo. Seu desenvolvimento ocorre em gengiva e processo alveolar como resultado de fatores irritativos locais. Apresenta-se como uma massa nodular avermelhada. É frequentemente recoberta por exsudato fibrinoso em áreas ulceradas e geralmente ocorre na forma pediculada. A prevalência é maior em pacientes adultos, mulheres, e na mandíbula. Histologicamente pode-se observar uma proliferação de células gigantes multinucleadas em meio a muitas células mesenquimais ovóides fusiformes e células de inflamação crônicas. Paciente do sexo masculino, 13 anos, chega à Clínica de Estomatologia da UFPR queixando-se de aumento de volume doloroso à mastigação $e$ com sangramento espontâneo, localizado na região retromolar inferior esquerda. Observou-se uma lesão pediculada, com diâmetro aproximado de $5 \mathrm{~cm}$ e com características clínica de uma LPCG. Radiograficamente não se observou a reabsorção óssea em forma de taça. Optou-se por remoção excisional com posterior curetagem do tecido ósseo e envio da peça para exame anatomo-patológico. Após quinze dias o paciente retornou com a mucosa íntegra e ausência de sintomatologia. Trinta e cinco dias após o paciente encontra-se com pós-operatório estável.

Palavras-chave: Lesão Periférica de Células Gigante; Granuloma de Células Gigantes; Granuloma Reparativo de Células Gigantes. 